\title{
TĂNG TRIRELYCERIE MÁU RẤT NĂNG Ở BỆNH NHÂN VIÊM TỤY CẤP: YẾU TỐ NGUY CƠ VÀ̀ KẾT CỰC LÂM SÀNG
}

\author{
Võ Duy Thông1,3, Nguyễn Thị Mộng Trinh², Hồ Tấn Phát ${ }^{3}$
}

TÓM TẮT

Mục tiêu: Đánh giá mối liên quan giữa một số yếu tổ lâm sàng, cận lâm sàng và kết cục của bệnh nhân (BN) viêm tuỵ cấp (VTC) do tăng triglycerid (TंG) với phân độ năng của tăng TG theo Hội nôi tiết Mỹ 2010. Đối tượng và phương pháp nghiên cứu: Nghiên cứu hồi cứu 132 BN VTC do tăng TG nhâp viên tại Bệnh viện Chợ Rẫy từ tháng 1 năm 2017 đến tháng 5 năm 2019. BN VTC do tăng TG được chia thành hai nhóm theo phân độ nặng của tăng TG theo Hô̂i nôi tiết: tăng TG rất nặng ( $\geq 2000 \mathrm{mg} / \mathrm{dL}$ ) và tăng TG nặng (1000 - 1999 mg/dL). Giá trị TG được ghi nhân trong vòng 48 giờ đầu sau nhập viện. Tiến hành phẩn tích sự khác nhau giữa hai nhóm này trong mối liên quan với các yếu tố nhân trắc học, đăc điểm lâm sàng, cận lâm sàng và kết cục của BN VTC do tăng TG. Kết quả: So với nhóm tăng TG nặng, trung bình hemoglobin $(\mathrm{Hb})$ ở BN VTC do tăng TG cao hơn có ý nghĩa so với nhóm tăng TG rất nặng $(p=0,017)$. Có sư khác nhau về thời gian prothrombin $(P T)(p=0,001)$, creatinine $(p=0,011)$ và CRP giờ thứ 48 sau nhập viên $\left(C P_{48}\right)(p=0,019)$ giữa hai nhóm. Tần suất về tiền căn rối loạn lipid máu cao hơn một cách có ý nghĩa ở nhóm tăng TG rất năng $(p=0,022)$. Phân tích đa biến chứng minh tiền căn tăng $\mathrm{TG}$ và $\mathrm{CRP}_{48}$ liên quan có ý nghĩa thống kê ở nhóm VTC tăng TG rất nặng $(p<0,05)$. Kết luận: Ở BN VTC do tăng TG, nhóm tăng TG rất nă̆ng có trung bình $\mathrm{Hb}$ cao hơn, $\mathrm{PT}$ ngắn hơn và creatinine thấp hơn một cách có ý nghĩa thống kê khi so sánh với nhóm tăng TG nặng. Trong phân tích đa biến, nhóm tăng TG rất nặng liên quan đến tiền căn loan lipid máu và giá trị CRP giờ $48(p<0,05)$.

Tư khóa: viêm tụy cấp, viêm tụy cấp do tăng triglycerid, tăng triglycerid rất nặng

\section{SUMMARY}

\section{FACTORS AND OUTCOMES RELATED TO THE VERY SEVERE HYPERTRIGLYCERIDEMIA IN PATIENTS WITH HYPERTRIGLYCERIDEMIA INDUCED ACUTE PANCREATIIIS}

Objectives: The aims of this study were to assess the relationship between clinical factors, biochemical data and outcomes in patients with hypertriglyceride induced acute pancreatitis (HTGP) and the grades of hypertriglyceridemia (HTG) by Endocrine Society 2010. Methods: We retrospectively analyzed a total

${ }^{1}$ Dai hoc Y Dước TP. Hồ Chí Minh

2Trường Đại học Trà Vinh

${ }^{3}$ Bệnh viện Chợ Rẫy

Chịu trách nhiệm chính: Võ Duy Thông

Email: duythong@ump.edu.vn

Ngày nhận bài: 6.01.2021

Ngày phản biện khoa học: 2.3.2021

Ngày duyệt bài: 12.3.2021 of 132 patients with HTGP from January 2017 to May 2019 at Cho Ray Hospital. HTGP patients were divided into two groups according to the grades of HTG by Endocrine Society: very severe HTG $(\geq 2000 \mathrm{mg} / \mathrm{dL})$ and severe HTG (1000 - $1999 \mathrm{mg} / \mathrm{dL})$. Serum TG levels measured within 48 hours of admission. We analyzed the differences between two groups of patients, including general infomation, clinical characteristics, biochemical data and outcomes. Results: Comparing with the severe HTG group, the mean of hemoglobin $(\mathrm{Hb})$ had significantly higher level in the very severe HTG group $(p=0.017)$. There were significant differences in level of prothrombin time (PT) $(p=0.001)$, creatinine $(p=0.011)$ and the grade of creactive protein at 48 hours after admission $\left(\mathrm{CRP}_{48}\right) \quad(p=0.019)$ between the two groups. The prevalence of history of dyslipidemia was significantly high in the very severe HTG group $(p=0.022)$. Multivariate analysis demonstrated that history of dyslipidemia and level of $\mathrm{CRP}_{48}$ were statistically significant relating with the very severe HTG $(p<0.05)$. Conclusions: In patients with HTGP, there were significantly higher of $\mathrm{Hb}$ and lower of $\mathrm{PT}$ and creatinine in patients with the very severe HTG as compared to the severe HTG. According to the multivariate analysis, history of dyslipidemia and levels of $\mathrm{CRP}_{48}$ were significant related to the very severe HTG ( $p<0.05)$.

Keywords: acute pancreatitis, hypertriglyceridemia induced acute pancreatitis, very severe hypertriglyceridemia.

\section{I. ĐĂT VẤN ĐỀ}

Viêm tụy cấp (VTC) là tình trạng viêm cấp tính của tuyến tụy, có khoảng 5 đến $10 \%$ BN VTC đe dọa tính mạng và tử vong đáng kể [1], [2]. Những hiểu biết hiện tại về nguyên nhân và cơ chế của VTC thì liên quan trực tiếp đến kết cục thuận lợi, ngăn ngừa VTC tái phát và quản lý BN VTC tốt hơn [3]. Tăng TG được xem là nguyên nhân thường gặp hàng thứ ba của VTC, trong đó tăng TG nặng và tăng TG rất nặng làm tăng nguy cơ VTC, trong khi tăng TG nhẹ hoặc trung bình có thể là yếu tố nguy cơ tim mạch [3]. Nguyên nhân tăng TG có thể nguyên phát (như bất thường gen chuyển hóa lipid) hoặc thứ phát do rượu, đái tháo đường không kiểm soát, thai kỳ, béo phì, sử dụng estrogen, chế độ ăn và thuốc [4]. Tăng TG thường xảy ra sau yếu tố thứ phát ở những người có bất thường gen chuyển hóa lipid trước đó [3]. Một vài nghiên cứu đã chỉ ra, VTC do tăng TG và tăng TG máu cao liên quan đến sự trâm trọng của BN VTC [5], [6]. Tại Việt Nam, hiên có một vài nghiên cứu về VTC tăng TG đã và đang được nghiên cứu sâu hơn [7], [8], các nghiên cứu về 
VTC do tăng TG còn khá ít và hiện chưa có nghiên cứu nhận diện các yếu tố liên quan đến phân độ nặng của tăng TG trên nhóm dân số VTC do tăng TG. Do vậy để góp phần làm rõ hơn và có thêm thông tin về đặc điểm của bệnh đồng thời xác định yếu tố nào liên quan đến phân độ nặng của tắng TG ở nhóm dân số VTC do tăng TG là cần thiết và quan trọng trong việc quản lý BN VTC. Nghiên cứu của chúng tôi được thực hiện nhằm đánh giá mối liên quan giữa một số yếu tố lâm sàng, cận làm sàng và kết cục của BN VTC do tăng TG với phân độ nặng của tăng TG theo Hội nội tiết Mỹ 2010.

\section{II. ĐỐI TƯỢNG VÀ PHƯƠNG PHÁP NGHIÊN CỨU}

Thiết kế nghiên cứu: Nghiên cứu cắt ngang hồi cứu có phân tích.

Đối tượng nghiên cứu: $\mathrm{BN}$ đủ 18 tuổi trở lên, thỏa tiêu chuẩn chẩn đoán của VTC, được chẩn đoán tăng TG máu với nồng độ $T G \geq 1000$ $\mathrm{mg} / \mathrm{dL}$ và loại trừ nguyên nhân khác. Xét nghiệm TG máu được thực hiện trong vòng 48 giờ sau nhập viện. Không nhận vào nghiên cứu những $B N$ viêm tựy mạn, BN có bệnh lý mạn tính nặng chưa kiểm soát được (xơ gan, bệnh lý ác tính, bệnh tự miễn,...) và không đủ thông tin cần thiết.

Phương thức tiến hành. Các $B N$ thỏa tiêu chuẩn chọn bệnh nhập khoa Nội Tiêu hóa-Bệnh viện Chợ Rẫy từ tháng 1 năm 2017 đến tháng 5 năm 2019. Ghi nhận các thông tin về chỉ số nhân trắc học, nghề nghiệp, tiền căn, lý do vào viện, dấu hiệu sinh tồn, tri giác theo thang điểm Glasgow, độ bão hòa oxy máu, triệu chứng lâm sàng, tất cả xét nghiệm tại thời điểm nhập viện và theo dôi trong thời gian nằm viện (công thức máu, PT, APTT, AST, ALT, BUN, creatinine, glucose, TG, bilirubin, ion đồ, CRP giờ 48 sau nhập viện (CRP48), amylase máu, lipase máu, siêu âm bụng tổng quát, $\mathrm{CT}$ bụng cản quang và Xquang ngực thẳng, khí máu động mạch, ceton máu), biến chứng tại chỗ, biến chứng toàn thân, suy tạng và kết cục lâm sàng (VTC nặng, thời gian nằm viện, nhập ICU, bệnh nặng tử vong hoặc xin về). Phân loại mức độ tăng TG huyết thanh theo Hướng dẫn thực hành lâm sàng của Hội Nội tiết 2010 [3]: tăng TG nặng (1000 - 1999 $\mathrm{mg} / \mathrm{dL})$ và tăng TG rất nặng ( $\geq 2000 \mathrm{mg} / \mathrm{dL})$. Sau đó tiến hành phân tích mối liên quan giữa các yếu tố trên trong mối liên quan với phân độ nặng của tăng TG theo Hội nội tiết của Mỹ ở nhóm dân số VTC do tăng TG. Tất cả BN VTC do tăng TG được điều trị cơ bản và được can thiệp giảm TG bằng thay huyết tương, insulin hoặc fenofibrate. Lưu đồ nghiên cứu như sơ đồ 1.
Tiêu chuẩn và định nghĩa: Chẩn đoán VTC do tăng TG được thiết lập khi hiện diện đồng thời 2 tiêu chí sau [2]: (1) BN được chẩn đoán VTC theo phân độ Atlanta hiệu chỉnh 2012 và (2) VTC có tăng TG máu $\geq 1000 \mathrm{mg} / \mathrm{dL}$ và loại trừ nguyên nhân khác. Phân loại mức độ tăng TG huyết thanh theo Hướng dẫn thực hành lâm sàng của Hội nội tiết 2010 [1]: tằng TG nặng $(1000-1999 \mathrm{mg} / \mathrm{dL})$ và tăng TG rất nặng $(\geq$ 2000 mg/dL). Biến chứng [2]: Biến chứng tại chỗ bao gồm tụ dịch cấp tính quanh tụy, hoại tử tụy, viêm tụy hoại tử nhiễm trùng, nang giả tụy, suy giảm chức năng thoát của dạ dày, huyết khối tĩnh mạch cửa và hoại tử ruột. Biến chứng hệ thống là đợt kịch phát của các bệnh lý nội khoa mạn tính liên quan đến VTC (bệnh động mạch vành, đái tháo đường,... ).

Tiêu chuẩn nhập ICU của Bệnh viện Chợ Rẫy: có chỉ định thay huyết tương, lọc máu liên tục và hoặc bệnh nặng có suy cơ quan. Tử vong nội viện: $B N$ tử vong trong bệnh viện hoặc bệnh nặng xin về. Số ngày nằm viện: thời gian từ lúc $B N$ vào viện đến lúc ra viện (BN còn sống) hoặc bênh ổn chuyển đến y tể địa phương theo dỗi tiếp. Bằng ngày ra viện - ngày vào viện.

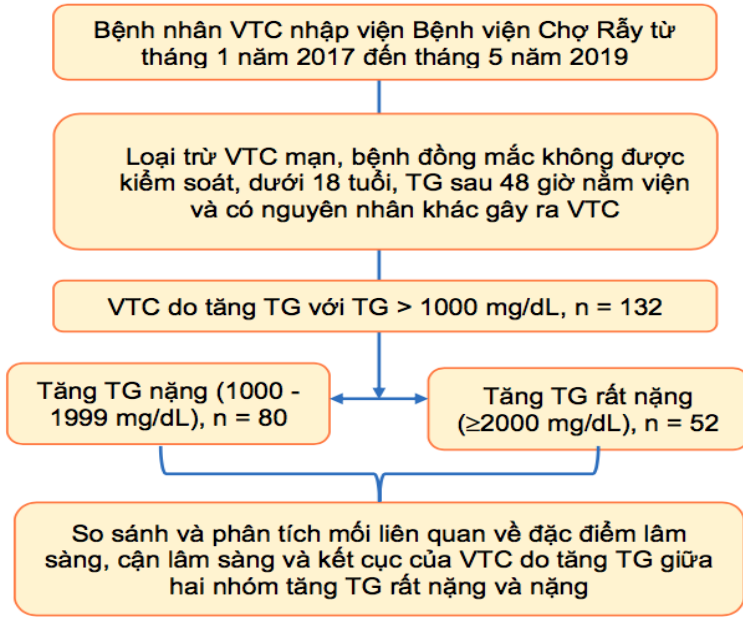

Sơ đồ 1. Lưu đồ nghiên cứu

Phân tích thống kê: Các số liệu được xử lý và phân tích bằng phần mềm SPSS 20.0; giá trị $p<0,05$ được coi là có ý nghĩa thống kê. Các khoảng tin cậy được trình bày ở mức giới hạn $95 \%$. Các biến định lượng được trình bày dưới dạng trung bình \pm độ lệch chuẩn (phân phối chuẩn); trung vị và khoảng tứ vị (phân phối không chuẩn). Phép kiểm Kolmogorov - Smirnov dùng để kiếm định phân phối chuẩn. Các biến định tính được trình bày dưới dạng tỷ lệ phần trăm. Để so sánh giữa các biến định lượng và biến định tính, chúng tôi dùng phép kiểm chi - 
square, " $t$ " và Mann Whitney. Để phân tích vai trò từng yếu tố liên quan đến một biến số dùng phương pháp hồi qui logistic đa biến.

Đao đức trong nghiên cứu: Nghiên cứu này đã được sự chấp thuận của Hội đồng đạo đức trong nghiên cứu y sinh học Đại học Y Dược Thành phố Hồ Chí Minh.

\section{KẾT QUẢ NGHIÊN CứU}

Có $132 \mathrm{BN}$ được nhận vào nghiên cứu trong thời gian từ tháng $1 / 2017-5 / 2019$. Trong đó, có $52 \mathrm{BN}$ thuộc nhóm tăng TG rất nặng ( $\geq 2000$ $\mathrm{mg} / \mathrm{dL}$ ) và $80 \mathrm{BN}$ thuộc nhóm tăng TG nặng $(1000-1999 \mathrm{mg} / \mathrm{dL})$. Đặc điểm dân số nghiên cứu giữa 2 nhóm như bảng 1 . Đặc điểm cận lâm sàng và kết cục của BN VTC do tăng TG giữa 2 nhóm như bảng 2, bảng 3 và bảng 4 .

Mối liên quan giữa yếu tố lâm sàng và cận lâm sàng với phân độ nặng của tăng TG ở BN VTC do tăng TG. Chúng tôi tìm thây mối liên quan có ý nghĩa thống kê giữa phân độ tăng TG rất nặng với nhóm BN có tiền căn rối loạn lipid máu với $p$ là $0,022(\mathrm{OR}=3,1 ; 95 \% \mathrm{CI}: 1,1-$ $8,6)$ (bảng 1). Rối loạn lipid máu là một trong các yếu tố nguy cơ thứ phát gây tăng TG [4]. Chúng tôi không tìm thây mối liên quan có ý nghĩa thống kê giữa phân độ tăng TG rất nặng và tuổi trung bình của $B N$ và nhóm $B N$ có các đặc điểm $B M I$ thừa - cân béo phì, giới tính nam, tiền căn VTC, đái tháo đường (ĐTĐ), tăng huyết áp (THA), sử dụng rượu và thuốc (Estrogen) $(p>0,05)$.

Đặc điểm cận lâm sàng và kết cục của BN VTC do tăng TG theo phân độ tăng TG. Tìm thấy mối liên quan có ý nghĩa thống kê giữa phân độ tăng TG rất nặng với $\mathrm{Hb}, \mathrm{PT}$, creatinine và $\mathrm{CRP}_{48} \quad(>150 \mathrm{mg} / \mathrm{L})$ (bảng 2). Cụ thể, nhóm tăng TG rất nặng có chỉ số $\mathrm{Hb}$ dài hơn, CRP và creatinin thấp hơn, thời gian PT ngắn hơn so với nhóm tăng $T G$ nặng với $p$ lần lượt là 0,017 ; 0,$019 ; 0,011$ và 0,001 . Không có sự khác nhau về giá trị của $\mathrm{HC}, \mathrm{Hct}, \mathrm{BC}, \mathrm{TC}, \mathrm{APTT}$, natri, kali, BUN, creatinine, glucose và tî số Neutrophil/ Lymphocyte (N/L) giữa 2 nhóm tăng TG rất nặng và tăng TG nặng với $p>0,05$ (bảng 2).

Bảng 1. Mối liên quan giữa đặc điểm lâm sàng và phân độ nặng của tăng TG theo Hội nội tiết của Mỹ ở BN VTC do tăng TG

\begin{tabular}{|c|c|c|c|c|c|}
\hline & Biến & $\begin{array}{c}\text { Tăng TG rất } \\
\text { nặng }(n=52)\end{array}$ & $\begin{array}{c}\text { Tăng TG năng } \\
(\mathbf{n}=\mathbf{8 0})\end{array}$ & $x^{2}$ or $t$ & $\mathbf{P}$ \\
\hline & Tuối, $M \pm$ SD & $39,6 \pm 6,7$ & $41,6 \pm 10,3$ & $-1,203$ & 0,231 \\
\hline Giới & Nam & $39(38,2 \%)$ & $63(61,8 \%)$ & $0.8(04-18)$ & 0.615 \\
\hline tính & Nữ & $14(40 \%)$ & $21(60 \%)$ & $0,8(0,4-1,8)$ & 0,015 \\
\hline & $M \pm S D$ & $23,9 \pm 2,8$ & $24,3 \pm 2,8$ & $-0,761$ & 0,448 \\
\hline BIMII & $\geq 23 \mathrm{~kg} / \mathrm{m}^{2}$ & $31(36 \%)$ & $55(64 \%)$ & $0,7(0,3-1,4)$ & 0,282 \\
\hline & iền căn VTC, n(\%) & $20(44,4 \%)$ & $25(55,6 \%)$ & $1,3(0,7-2,9)$ & 0,393 \\
\hline & ĐTÐ, $\mathrm{n}(\%)$ & $21(46,7 \%)$ & $24(53,3 \%)$ & $1,5(0,8-3,3)$ & 0,219 \\
\hline & THA, n(\%) & $10(43,5 \%)$ & $13(56,5 \%)$ & $1,2(0,5-3,1)$ & 0,659 \\
\hline & ử dụng rượu, n(\%) & $14(42,4 \%)$ & $19(57,6 \%)$ & $1,2(0,5-2,6)$ & 0,681 \\
\hline & loạn lipid máu, n(\%) & $12(63,2 \%)$ & $7(36,8 \%)$ & $3,1(1,1-8,6)$ & 0,022 \\
\hline & Lốc (Estrogen), n(\%) & $2(100 \%)$ & $0(0 \%)$ & - & 0,153 \\
\hline
\end{tabular}

$\mathrm{M} \pm \mathrm{SD}$ : trung bình \pm độ lệch chuẩn

Trong nghiên cứu của chúng tôi, có $89,4 \%$ được làm xét nghiệm amylase máu và $39,4 \%$ được làm xét nghiệm lipase máu lúc nhập viện. Khồng có sự khác nhau về giá trị amylase máu và lipase máu giữa 2 nhóm tăng TG rất nặng và tăng TG nặng $(p>0,05)$. Giá trị amylase máu và lipase máu tăng gấp 3 lần giới hạn trên bình thường ở nhóm tăng TG rất nặng chiếm tỷ lệ lần lượt là $48,8 \%$ và $28,8 \%$ (bảng 3 ).
Khi so sánh kết cục ở BN VTC do tăng TG, không tìm thấy sự khác nhau về thời gian nằm viện, nhập ICU, suy cơ quan, suy tạng dai dẵng và hoại tử tụy giữa 2 nhóm tăng TG rất nặng và tăng TG nặng $(p>0,05)$. Tỉ lệ tử vong không khác nhau giữa 2 nhóm tăng TG rất nặng và tăng TG nặng $(\mathrm{OR}=4,8 ; 95 \% \mathrm{CI}$ : $0,5-47,8$; $p=0,300)$. Nhóm tăng TG rất nặng không có mối liên quan với mức độ nặng của VTC do tăng TG ( $\mathrm{OR}=1,0 ; 95 \% \mathrm{CI}: 0,4-2,7 ; \mathrm{p}=0,952)$.

Bảng 2. Mối liên quan giữa đặc điểm cận lâm sàng và phân độ nặng của tăng TG theo hội nội tiết của Mỹ ở BN VTC do tăng TG

\begin{tabular}{|c|c|c|c|c|}
\hline Biến & $\begin{array}{c}\text { Tăng TG rất nặng } \\
(\mathbf{n}=\mathbf{5 2})\end{array}$ & $\begin{array}{c}\text { Tăng TG năng } \\
(\mathbf{n}=\mathbf{8 0})\end{array}$ & X2 or t or U & $\mathbf{P}$ \\
\hline $\mathrm{HC}, \mathrm{M} \pm \mathrm{SD}$ & $5,0 \pm 0,7$ & $5,0 \pm 0,8$ & $-1,180$ & 0,858 \\
\hline $\mathrm{Hb}, \mathrm{M} \pm \mathrm{SD}$ & $16,0 \pm 2,3$ & $15,0 \pm 2,4$ & 2,412 & $\mathbf{0 , 0 1 7}$ \\
\hline
\end{tabular}


VIETNAM MEDICAL JOURNAL N² - MARCH - 2021

\begin{tabular}{|c|c|c|c|c|}
\hline $\mathrm{Hct}, \mathrm{M} \pm \mathrm{SD}$ & $43,2 \pm 6,4$ & $44,0 \pm 6,1$ & $-0,711$ & 0,478 \\
\hline $\mathrm{CRP}_{48}, \mathrm{M} \pm \mathrm{SD}$ & $225,2 \pm 106,0$ & $263,1 \pm 109,6$ & $-1,966$ & 0,051 \\
\hline $\mathrm{TC}, \mathrm{M} \pm \mathrm{SD}$ & $248,0 \pm 90,5$ & $224,0 \pm 72,4$ & 1,685 & 0,094 \\
\hline $\mathrm{BC}$, trung vi & 64,3 & 68,0 & 1965,0 & 0,592 \\
\hline PT, trung vị & 53,0 & 75,3 & 1375,5 & 0,001 \\
\hline APT, trung vi & 69,0 & 65,0 & 1950,5 & 0,546 \\
\hline Glucose, trung vị & 80,0 & 64,3 & 1904,0 & 0,412 \\
\hline BUN, trung vị & 60,6 & 70,3 & 1773,5 & 0,153 \\
\hline Creatinine, trung vi! & 56,1 & 73,3 & 1536,5 & 0,011 \\
\hline Natri, trung vị & 61,9 & 69,5 & 1840,0 & 0,262 \\
\hline Kali, trung vị & 65,1 & 67,4 & 2006,5 & 0,732 \\
\hline Tỉ số $\mathrm{N} / \mathrm{L}$, trung vị & 66,2 & 66,7 & 2066,0 & 0,948 \\
\hline Hct $>44 \% *, n(\%)$ & $5(38,5 \%)$ & $8(61,5 \%)$ & $1,0(0,3-3,1)$ & 0,942 \\
\hline BUN >20mg/dL*, n (\%) & $7(28,0 \%)$ & $18(72,0 \%)$ & $0,5(0,2-1,4)$ & 0,195 \\
\hline Creatinine $>1,9 \mathrm{mg} / \mathrm{dL}, \mathrm{n}(\%)$ & $5(35,7 \%)$ & $9(64,3 \%)$ & $0,8(0,3-2,7)$ & 0,766 \\
\hline $\mathrm{CRP}_{48}>150 \mathrm{mg} / \mathrm{L}, \mathrm{n}(\%)$ & $37(34,6 \%)$ & $70(65,4 \%)$ & $0,3(0,1-0,9)$ & 0,019 \\
\hline Glucose $\geq 200 \mathrm{mg} / \mathrm{dL}$ & $33(42,3 \%)$ & $45(57,7 \%)$ & $1,8(0,9-3,7)$ & 0,109 \\
\hline Natri máu< $135 \mathrm{mEq} / \mathrm{L}$ & $36(39,6 \%)$ & $55(60,4 \%)$ & $1,4(0,7-2,8)$ & 0,410 \\
\hline
\end{tabular}

*sau bù dịch; $\mathrm{M} \pm \mathrm{SD}$ : trung bình \pm độ lệch chuấn

Bảng 3, Amylase và lipase máu ở BN VTC do tăng TG theo phân độ nặng của tăng TG

\begin{tabular}{|c|c|c|c|c|}
\hline Biến & $\begin{array}{l}\text { Tăng TG rất } \\
\text { nặng, } \mathrm{n}(\%)\end{array}$ & $\begin{array}{c}\text { Tăng TG } \\
\text { nặng, } \mathrm{n}(\%)\end{array}$ & $x^{2}$ or $\mathbf{t}$ or $\mathbf{U}$ & $\begin{array}{c}\mathbf{P} \\
\text { value }\end{array}$ \\
\hline \multicolumn{5}{|c|}{ Số trường hợp thực hiện xét nghiệm amylase máu, $\mathrm{n}=118$} \\
\hline $\begin{array}{c}\text { Amylase }(\mathrm{U} / \mathrm{L}) \geq 3 \text { lần giới } \\
\text { han trên bình thường, } n=43\end{array}$ & $21(48,8 \%)$ & $22(51,2 \%)$ & $1,9(0,9-4,1)$ & 0,097 \\
\hline \multicolumn{5}{|c|}{ Số trường hợp thực hiện xét nghiệm lipase máu, $n=73$} \\
\hline $\begin{array}{l}\text { Lipase }(\mathrm{U} / \mathrm{L}) \geq 3 \text { lần giới hạn } \\
\text { trên bình thường, } \mathrm{n}=52\end{array}$ & $15(28,8 \%)$ & $37(71,2 \%)$ & $0,8(0,3-2,4)$ & 0,705 \\
\hline
\end{tabular}

Bảng 4, So sánh kết cục ở BN VTC do tăng TG giữa hai nhóm tăng TG

\begin{tabular}{|c|c|c|c|c|c|}
\hline & Biến & $\begin{array}{l}\text { Tăng TG rất } \\
\text { năng }(\mathrm{n}=52)\end{array}$ & $\begin{array}{c}\text { Tăng TG năng } \\
(\mathbf{n}=\mathbf{8 0})\end{array}$ & $x^{2}$ or $U$ & $\mathbf{p}$ \\
\hline Suy & ô hấp, n (\%) & $11(27,9 \%)$ & $24(72,1 \%)$ & $0,6(0,3-1,4)$ & 0,261 \\
\hline & thận, n (\%) & $7(38,9 \%)$ & $11(61,1 \%)$ & $1,0(0,4-2,7)$ & 0,962 \\
\hline Suyt & $\mathrm{n}$ mach, $\mathrm{n}(\%)$ & $5(55,6 \%)$ & $4(44,4 \%)$ & $2,0(0,5-7,9)$ & 0,304 \\
\hline Suy tạ & kéo dài, n (\%) & $8(40,0 \%)$ & $12(60 \%)$ & $1,0(0,4-2,7)$ & 0,952 \\
\hline Hoạ & Eư tụy, n (\%) & $10(27,0 \%)$ & $27(73,0 \%)$ & $0,5(0,2-1,1)$ & 0,070 \\
\hline & Nặng, n (\%) & $8(40,0 \%)$ & $12(60,0 \%)$ & & \\
\hline $\begin{array}{l}\text { tăng TG } \\
\text { tăn do }\end{array}$ & $\begin{array}{l}\text { Nhè/trung bình } \\
\text { nặng, n (\%) }\end{array}$ & $44(39,3 \%)$ & $68(60,7 \%)$ & $1,0(0,4-2,7)$ & 0,952 \\
\hline Thời giar & רằm viện, trung vị & 66,5 & 66,5 & 2079,0 & 0,996 \\
\hline $\mathrm{Nh}$ & $\mathrm{ICU}, \mathrm{n}(\%)$ & $13(52,0 \%)$ & $12(48,0 \%)$ & $1,9(0,8-4,5)$ & 0,152 \\
\hline & ong, $\mathrm{n}(\%)$ & $3(75 \%)$ & $1(25 \%)$ & $4,8(0,5-47,8)$ & 0,300 \\
\hline Phân t & h hồi quy nhị ph & n đa biến. Kết & Biến & OR (95\% CI) & $\mathbf{p}$ \\
\hline quả phân t & h hồi quy đa biến & bảng 5. Phân & Rối loạn lipid máu & $0,3(0,1-0,8)$ & 0,022 \\
\hline & chúng minh tiân & rối loạn lipid & $\mathrm{Hb}$ & $0,8(0,7-1,0)$ & 0,019 \\
\hline & $050 \%$ CT. 01 & & PT & $1,4(1,0-1,9)$ & 0,043 \\
\hline & & & Creatinine & $1,2(0,7-1,9)$ & 0,568 \\
\hline & IT & & $\mathrm{CRP}_{48}>150 \mathrm{mg} / \mathrm{L}$ & $2,8(1,1-7,3)$ & 0,037 \\
\hline
\end{tabular}

BN có mức tăng TG rất nặng.

Bảng 5. Hồi quy nhị giá đa biến ở BN VTC do tăng TG trong mối liên quan giữa các yêu tố lâm sàng và cận lâm sàng với phân độ tăng TG rất nặng theo Hội nội tiêt 2010

\section{BÀN LUẬN}

Trong nghiên cứu của chúng tôi, VTC do tăng TG với mức TG trên $1000 \mathrm{mg} / \mathrm{dL}$, sau kiểm tra phân phối của giá trị TG có phân phối không chuẩn, lệch về bên trái, chúng tôi tiến hành 
phân chia mức tăng TG theo Hội Nội tiết của Mỹ 2010 thành nhóm nặng $(1000-1999 \mathrm{mg} / \mathrm{dL})$ và rất nặng (> 2000 mg/dL) với tỷ lệ chiếm lần lượt là $39,4 \%$ và $60,6 \%$ (trung vị TG là 1436,96 $\mathrm{mg} / \mathrm{dL}$ và khoảng tứ vị là $(1209,5-2807,0)$ $\mathrm{mg} / \mathrm{dL}$ ). Ngưỡng giá trị của TG sẽ khác nhau giữa các nghiên cứu khi tiến hành phân chia mức độ tăng TG, điều này có thể phụ thuộc vào thời điểm chẩn đoán, tiêu chuẩn phẩn loai tăng TG, dân số nghiên cứu, yếu tố nguy cơ gây tăng TG và thời điểm lấy mẫu TG thử. Nồng độ TG giảm nhanh sau nhịn đói $24-48$ giờ. Chúng tôi tiến hành so sánh các đăc điểm về giới tính, tuổi, BMI, tiền căn, đặc điểm lâm sàng, cận lâm sàng với mức độ tăng TG rất nặng và tăng TG nặng ở BN VTC do tăng TG để tìm xem yếu tố nào liên quan đến phân độ nặng của tăng TG.

Tuổi trung bình trong nghiên cứu của chúng tôi là 40,8 $\pm 9,1$. Tỉ số nam/nữ là 3,4/1. Không có sự khác nhau về tuổi trung bình, tỉ số giới tính và $B M I$ thừa cân - béo phì giữa hai nhóm $(p>0,05)$. Ở nhóm tăng TG rất nặng, không tìm thấy mối liên quan với tiền căn VTC $(\mathrm{OR}=1,3$; $95 \%$ CI: $0,7-2,9 ; p=0,393)$, ĐTÐ (OR=1,5; $95 \%$ CI: $0,8-3,3 ; p=0,219)$, THA (OR=1,2; $95 \% \mathrm{CI}: 0,5-3,1 ; p=0,659)$ và sử dụng rượu (OR=1,2; 95\% CI: $0,5-2,6 ; p=0,681)$ khi so với nhóm tăng TG nặng. Có Iẽ tiền căn VTC, ĐTÐ, sử dụng rượu là các yếu tố nguy cơ của VTC và VTC do tăng TG nên khi chúng tôi phân tích các yếu tố trên trong dân số VTC do tăng TG giữa nhóm tăng $T G$ rất nặng và tăng $T G$ nặng khác nhau không ý nghĩa thống kê. Chúng tồi tìm thấy mối liên quan có ý nghĩa thống kê giữa phân độ tăng TG rất nặng với nhóm BN có tiền căn rối loạn lipid máu với $p$ là $0,022(\mathrm{OR}=3,1$; $95 \%$ CI: $1,1-8,6)$. Rối loạn lipid máu là một trong các yếu tố nguy cơ thứ phát gây tăng TG [4]. Tăng TG thường xảy ra sau yếu tố thứ phát ổ những người có bất thường gen chuyển hóa lipid trước đó [1]. Tần suất rối loạn lipid máu trong nghiên cứu của chúng tôi thấp hơn nghiên cứu của Hoàng Đức Chuyên [7] và Wang SH [5]. Tỷ lệ này khác nhau phụ thuộc vào $B N$ có quan tâm đến vấn đề sức khỏe, tầm soát bênh hoặc BN có biết rối loạn lipid máu từ trước hoặc không theo dõi. Tiền cắn bệnh đồng mắc trong nghiên cứu của chúng tôi phù hợp với nghiên cứu của Wang SH [5] và Vipperla $K$ [6] về yếu tố thứ phát của tăng TG (ĐTÐ không kiểm soát/ không biết, béo phì, rượu, rối loạn lipid máu, thuốc,...).

VTC do tăng TG thứ phát sau sử dụng thuốc estrogen đã có báo cáo theo ca [4]. Trong nghiên cứu của chúng tôi, ghi nhận có 2 trường hợp VTC do tăng TG liên quan đến việc sử dụng thuốc ngữa thai dạng viên uống estrogen. Yếu tố nguy cơ có thể thây của VTC do tăng TG sau nguyên nhân estrogen bao gồm bất thường chuyển hóa lipid, đề kháng insulin, béo phì, sử dụng rượu và thai kỳ [4]. Thuốc estrogen có thể làm giảm $40 \%$ sự nhạy cảm insulin kèm theo tăng nồng độ $A B$ tự do, cholesterol, TG trong máu và có đáp ứng theo liều. VTC do tăng TG thứ phát sau nguyên nhân do thuốc thường ghi nhận ở mức độ nhẹ hoặc trung bình nặng [4]. Cả 2 trường hợp trong nghiên cứu của chúng tôi ghi nhận ở mức độ trung bình nặng và không tìm thẩy mối liên quan có ý nghĩa thống kê giữa phân độ tăng TG rất nặng và nhóm $B N$ có tiền căn sử dụng estrogen trên dân số VTC do tăng TG $(p=0,153)$. Sự khác nhau về yếu tố lâm sàng giữa các nghiên cứu phụ thuộc đặc điểm dân số nghiên cứu, nguyên nhân của VTC, thói quan sinh hoạt, thời gian thu thập số liệu, cõ mẫu mỗi phân nhóm và chọn ngưỡng tăng TG không đủ để tìm thấy sự khác biệt, có thể cần có những nghiên cứu tiến cứu với cớ mẫu lớn hơn để đánh giá khách quan hơn.

Trong nghiên cứu của chúng tôi, có $89,4 \%$ được làm xét nghiệm amylase máu và $39,4 \%$ được làm xét nghiệm lipase máu lúc nhập viện. Điều này phù hợp với giá trị amylase có thể thấp giả hoặc bình thường trong VTC do tăng TG [4]. Tỷ lệ tăng amylase và lipase máu sẽ khác nhau giữa các nghiên cứu là do mức chọn ngưỡng tăng, dân số VTC, thời điểm đo amylase và lipase máu. Không có sự khác nhau về giá trị amylase máu và lipase máu giữa 2 nhóm tăng TG rất nặng và tăng $T G$ nặng $(p>0,05)$. Giá trị amylase máu và lipase máu tăng gấp 3 lần giới hạn trên bình thường ở nhóm tăng TG rất nặng chiếm tỷ lệ lần lượt là $44,9 \%$ và $26,9 \%$ (bảng 3 ). Theo Scherer J [4], tăng lipid máu có thể can thiệp vào việc xác định nông độ amylase trong máu hoăc sự hiên diên của chất ức chế sự tồn tại của amylase. Amylase có thể bình thường giả tạo khi TG trong máu tăng $>500 \mathrm{mg} / \mathrm{dL}$ và có thể do xuất hiện hiện tượng kháng amylase. Pha loãng mẫu huyết thanh có thể làm giảm sự nhiễu của TG trong máu. Lipase ít bị ảnh hưởng bởi sự tăng TG máu.

Theo Sheng-Huei Wang [5], nồng độ glucose máu, cholesterol toàn phần và BUN cao đáng kế ở nhóm BN VTC do tăng TG có mức TG > 2468 $\mathrm{mg} / \mathrm{dL}$ khi so sánh với nhóm có TG $<2468$ $\mathrm{mg} / \mathrm{dL}$, trong khi đó nồng độ bicabonate và natri thấp đáng kể ở nhóm có mức TG $>2468 \mathrm{mg} / \mathrm{dL}$ $(p<0,05)$. Trong nghiên cứu này, không tìm 
thấy mối liên quan có ý nghĩa thống kê giữa giá trị amylase, lipase, albumin, LDH, acid uric và CRP giữa 2 nhóm trên. Trong nghiên cứu của chúng tôi, nhóm tăng TG rất nặng có giá trị $\mathrm{Hb}$ cao hơn $(p=0,017)$, $P T$ ngắn hơn $(p=0,001)$ và creatinine thấp hơn $(p=0,011)$.

Ở nhóm tăng TG rất nặng, giá trị CRP giờ thứ 48 sau nhập viện thấp hơn một cách có ý nghĩa khi so với nhóm tăng TG nặng $(\mathrm{OR}=0,3 ; 95 \%$ CI: $0,1-0,9 ; p=0,019)$. Lý giải điêuu này, theo Leppaniemi $A$ [3], CRP tăng lên cùng với chỉ số khối cơ thể, có một mối tương quan dương trung gian giữa CRP và $B M I(>23 \mathrm{~kg} / \mathrm{m} 2$ với $p<0,01)$ và TG cho thấy mối tương quan âm tính yếu. Nếu trung bình BMI tăng 1 đơn vị, CRP tăng 0,239 lần và CRP tăng đáng kể. Trong khi trung bình tăng 1 đơn vị chất béo trung tính làm cho CRP giảm $-0,006$ lần nhưng giá trị này không đáng kể. Điều này giải thích tại sao giá trị CRP48 $>150 \mathrm{mg} / \mathrm{dL}$ thấp hơn ở nhóm VTC do tăng TG có TG tăng rất nặng.

Không có sự khác nhau về giá trị của hồng cầu, Hct, bạch cầu, tiểu cầu, APTT, natri, kali, BUN, creatinine, glucose và tỉ số $\mathrm{N} / \mathrm{L}$ giữa 2 nhóm tăng TG rất nặng và tăng TG nặng với $p$ > 0,05 . Có thể là do ngưỡng tăng TG và cõ̃ mẫu trong nghiên cứu của chứng tôi không đủ để tìm thấy sự khác biêt.

Theo Wang SH [5], thời gian Prothrombin cao hơn ở nhóm TG $\geq 200 \mathrm{mg} / \mathrm{dL}$ khi so sánh với mức TG thấp hơn ngưỡng giá trị đó. Tăng Lipid máu có liên quan đến sự tăng hoạt động của hệ thống đông máu trong dân số bình thường vì vậy có thể giải thích cho kết quả đông máu ở BN tăng TG rất nặng so với nhóm tăng TG nặng. Trung bình $\mathrm{Hb}$ tại thời điểm nhập viện cao hơn một cách có ý nghĩa ở nhóm tăng TG rất nặng. Nó có thể bị ảnh hưởng bởi nồng độ TG tăng trong máu và tình trạng cô đặc máu trong bệnh cảnh của VTC.

Tăng TG là một yếu tố độc lập liên quan đến kết cục của BN VTC, đặc biệt là VTC do tăng TG khi so sánh với các nguyên nhân khác và từng mức tăng TG. Các nghiên cứu cho thấy VTC có mức TG tăng nặng và rất nặng có ảnh hưởng rõ rệt trên độ nặng của VTC, khả năng tái phát, biến chứng hoại tử tụy và các biến cố suy tạng nhiều hơn (tăng nồng độ TG trong máu liên quan độc lập đến suy tạng kéo dài), tăng nguy cơ biến chứng tại chố, hội chứng đáp ứng viêm kéo dài hơn, tần suất tự vong và thời gian nằm viện dài hơn [6], [8]. Trong nghiên cứu của Wang $\mathrm{SH}[5]$, thời gian nằm viện, suy tang, suy cơ quan dai dẵng, hoại tử tụy, nhập ICỦ và tỉ lệ tử vong tăng theo phân độ nặng của tăng TG $(p<0,001)$. Theo Scherer J et al. [4], biến cố suy cơ quan dai dẵng, suy tạng, hoại tử tụy ở nhóm VTC tăng TG cao hơn khi so với nhóm không tăng TG $(p<0,05)$. Trong nghiên cứu của chúng tôi, không tìm thấy sự khác nhau về thời gian nằm viện, nhập ICU, suy cơ quan, suy tạng dai dẵng và hoại tử tụy giữa 2 nhóm tăng TG rất nặng và tăng $T G$ nặng $(P>0,05)$. Tỉ lệ tử vong không khác nhau giữa 2 nhóm này $(\mathrm{OR}=5,5$; $95 \%$ CI: $0,6-54,2 ; p=0,136)$. Nhóm tăng TG máu rất nặng không có mối liên quan với mức độ nặng của VTC do tăng TG (OR=1,1;95\% CI: $0,4-2,8 ; p=0,855)$. Có lẽ do ngưỡng tăng $T G$ trong nghiên cứu của chúng tôi chưa đánh giá được sự khác nhau về ảnh hưởng của TG trên độ nặng trong VTC do tăng TG.

Trong tương lai, chúng ta cần có những nghiên cứu tiền cứu với cõ̃ mẫu lớn cũng như thiết lập ngưỡng tăng TG thích hợp trong dân số VTC do tăng TG để có thể hữu dụng trong đánh giá mối liên quan giữa đặc điểm lâm sàng, cận lâm sàng và kết cục ở BN VTC do tăng TG. Từ đó góp phần trong việc theo dõi lâm sàng, điều trị và quản lý BN VTC do tăng TG tốt hơn theo mức tăng TG và đề xuất phương pháp can thiệp hạ TG thích hợp. Nghiên cứu của chúng tôi có một vài hạn chế. Thứ nhất, đây là nghiên cứu hồi cứu. Thứ hai, cõ mẫu nghiên cứu nhỏ. Thứ ba, dữ liệu từ nghiên cứu có thể không đầy đủ do nghiên cứu hồi cứu. Thứ tư, hạn chế về thời gian lấy mấu, tần suất bệnh VTC do tăng TG có thể thấp hơn so với thực tế.

\section{KẾT LUÂ̂N}

Ở BN VTC do tăng TG, nhóm tăng TG rất nặng có trung bình $\mathrm{Hb}$, PT và creatinin cao hơn một cách có ý nghĩa thống kê khi so sánh với nhóm tăng TG nặng. Trong phân tích đa biến, nhóm tăng TG rất nặng liên quan đến tiền căn loạn lipid máu và giá trị CRP giờ $48(p<0,05)$. Trong tương lai, chúng ta cần nghiên cứu tiền cứu lớn hơn và ngưỡng giá trị tăng TG thích hợp để có thể đánh giá mối liên quan giữa phân độ tăng TG và kết cục của VTC do tăng TG ở BN VTC do tăng TG.

\section{TÀI LIỆ THAM KHẢO}

1. Berglund $\mathbf{L}$. et al. Evaluation and treatment of hypertriglyceridemia: an Endocrine Society clinical practice guideline. J Clin Endocrinol Metab. 2012; 97 (9), pp. 2969-2989.

2. Banks P. A. et al. Classification of acute pancreatitis-2012: revision of the Atlanta classification and definitions by international consensus. Gut. 2013; 62 (1), pp. 102. 
3. Leppaniemi A. et al. 2019 WSES guidelines for the management of severe acute pancreatitis. World J Emerg Surg. 2019; 14, pp. 27.

4. Scherer J. et al. Issues in hypertriglyceridemic pancreatitis: an update", J Clin Gastroenterol. 2014; 48 (3), pp. 195-203.

5. Wang S. H. et al. Relationship between Plasma Triglyceride Level and Severity of Hypertriglyceridemic Pancreatitis. PLoS One. 2016; 11 (10), pp. e0163984.
6. Vipperla K. et al. Clinical Profile and Natural Course in a Large Cohort of Patients With Hypertriglyceridemia and Pancreatitis. J Clin Gastroenterol. 2017; 51 (1), pp. 77-85.

7. Hoàng Đức Chuyên. Nghiên cứu đặc điểm lâm sàng, cận lâm sàng và điều trị viêm tuy cấp do tăng triglyceride. Trường Đại học Y Hà Nô̂i. 2012.

8. Huỹnh Tấn Đạt. Vai trò của tăng Triglyceride trong viêm tụy cấp. Đại học Y Dược Thành Phố Hồ Chí Minh. 2012.

\section{ĐĂC ĐIỂM SỬ DỤNG THUỐC ỨC CHẾ MIỄN DICCH SAU GHÉP VÀ MỐI LIÊN QUAN ĐẾN ĐÁI THÁO ĐƯỜNG SAU GHÉP THẬN}

\section{TÓM TẮT}

Mục tiêu: Phân tích đặc điểm sử dụng thuốc ức chế miễn dịch và mối liên quan đến đái tháo đường sau ghép trên đối tượng 3 tháng sau ghép thận. Đối tượng và phương pháp nghiên cứu: Gổm 508 bệnh nhân có thời gian sau ghép thận $\geq 3$ tháng được theo dõi và điều tri sau ghép tai BV Viêt Đức, từ 09/2017 đến 04/2018. Tất cả các bệnh nhân đều tự nguyện tham gia nghiên cứu. Bệnh nhân được lấy máu vào buổi sáng trước khi ăn và uống thuốc ức chế miễn dịch. Chẩn đoán đái tháo đường sau ghép tạng dựa trên tiêu chuẩn của Hiệp hội Đái tháo đường Hoa Kỳ (ADA - American Diabetes Association). Tất cả các bệnh nhân đều được sử dụng phác đồ chống thải ghép 2- 3 thuốc trong 3 nhóm thuốc theo quy trình của Bộ y tế. Kết quả: Tỉ lệ sử dụng thuốc ức chế theo thứ tự từ cao đến thấp như sau: MMF/MPA (92,32\%); prednisolon $(91,54 \%)$; tarcrolimus $(81,50 \%)$; basiliximab (75,59\%); cyclosporin A (17,72\%); everolimus $(6,10 \%)$. Hầu hết đối tượng sử dung các thuốc kể trên không cho sự khác biệt giữa phát triển NODAT và không NODAT; chỉ ở đổi tượng sử dụng corticoid tỉ lệ bệnh nhân bị NODAT là $12,47 \%$ trong khi không NODÁT chiếm $87,53 \%$ sư khác biệt có ý nghĩa thống kê với $p<0,001$. Kết luận: Điều chỉnh chế độ sử dung thuốc ức chế miễn dịch đặc biệt là corticoid có thể làm thay đổi nguy cơ phát triển đái tháo đường sau ghép thận.

Tư khóa: thuốc ức chế miễn dịch, đái tháo đường sau ghép thận

\section{SUMMARY \\ CHARACTERISTICS OF IMMUNOSUPPRESSIVE DRUGS AND ASSOCIATION WITH NEW-ONSET DIABETES AFTER RENAL TRANSPLANTATION}

\footnotetext{
${ }^{1}$ Bệnh viện Quân y 103

${ }^{2}$ Học viện Quân y

Chịu trách nhiệm chính: Đặng Thành Chung

Email: dangthanhchung@vmmu.edu.vn

Ngày nhận bài: 4.01.2021

Ngày phản biện khoa học: 5.3.2021

Ngày duyệt bài: 15.3.2021
}

\section{Nguyễn Đức Thuận ${ }^{1}$, Đặng Thành Chung²}

Objectives: To analyze the use of immunosuppressant drugs and the association with new-onset diabetes after renal transplantation (NODAT) in subjects three months post-transplantation. Subjects and methods: Including 508 patients with kidney post-transplant more than three months who are followed up and treated at Viet Duc University Hospital from September 2017 to April 2018. All patients volunteered to participate in the study. Collect blood samples of recipients in the morning before eating and taking immunosuppressants. Patients were diagnosed with new-onset diabetes after renal transplantation based on the American Diabetes Association (ADA). All patients received an anti-rejection regimen according to the procedure of Vietnam's Ministry of Health. Results: The ratio of using immunosuppressive drugs from high to low order as follows: MMF/MPA (92.32\%); prednisolone (91.54\%); tacrolimus (81, .50\%); basiliximab (75.59\%); cyclosporin A (17.72\%); everolimus (6.10\%). Most of the patients using these drugs did not show the difference of rate between developing NODAT and non-NODAT; Only in patients using corticosteroids, the rate of patients with NODAT was $12.47 \%$ non-NODAT accounted for $87.53 \%$, the difference was statistically significant with $p$ $<0.001$. Conclusion: Modifying an immunosuppressant regimen, especially corticoid, may alter the risk of developing diabetes after kidney transplantation.

Keywords: Immunosuppressive drugs, new-onset diabetes after renal transplantation.

\section{I. Đă̆T VẤN ĐỀ}

Mối liên quan giữa đái tháo đường mới mắc sau ghép thận (New-onset diabetes after transplantation - NODAT) và thuốc ức chế miễn dịch sử dụng sau cây ghép đã được ghi chép lại rõ̃ rệt [1], và là yếu tố chiếm tới $74 \%$ nguy cơ phát triển NODAT [2].Các tác nhân có liên quan nhiều nhất với NODAT là corticosteroid và tacrolimus $[3,4]$. Tăng kháng insulin và tăng cân được xem như là cơ chế chính liên quan đến corticosteroid gây ra NODAT [3]. Sự liên quan giữa corticosteroids và NODAT chủ yếu phụ 